\title{
Determining the instantaneous modulus of viscoelastic solids using instrumented indentation measurements
}

\author{
Yang-Tse Cheng ${ }^{\text {a) }}$ \\ Materials and Processes Laboratory, General Motors Research and Development Center, \\ Warren, Michigan 48090 \\ Wangyang Ni \\ Brown University, Providence, Rhode Island 02912 \\ Che-Min Cheng \\ Institute of Mechanics, Chinese Academy of Sciences, Beijing 100080, People's Republic of China
}

(Received 13 June 2005; accepted 2 August 2005)

\begin{abstract}
Instrumented indentation is often used in the study of small-scale mechanical behavior of "soft" matters that exhibit viscoelastic behavior. A number of techniques have recently been proposed to obtain the viscoelastic properties from indentation load-displacement curves. In this study, we examine the relationships between initial unloading slope, contact depth, and the instantaneous elastic modulus for instrumented indentation in linear viscoelastic solids using either conical or spherical indenters. In particular, we study the effects of "hold-at-the-peak-load" and "hold-at-the-maximum-displacement" on initial unloading slopes and contact depths. We then discuss the applicability of the Oliver-Pharr method (Refs. 29, 30) for determining contact depth that was originally proposed for indentation in elastic and elastic-plastic solids and recently modified by Ngan et al. (Refs. 20-23) for viscoelastic solids. The results of this study should help facilitate the analysis of instrumented indentation measurements in linear viscoelastic solids.
\end{abstract}

\section{INTRODUCTION}

Instrumented indentation is becoming a powerful tool for the study of small-scale mechanical behavior of "soft" matters, such as polymers, composites, biomaterials, and food products. Since many of these materials exhibit viscoelastic behavior, modeling of indentation in viscoelastic solids is essential. Theoretical studies of indentation in linear viscoelastic bodies can be traced back to the mid 1950s by the work of Lee, ${ }^{1}$ Radok, ${ }^{2}$ Lee and Radok, ${ }^{3}$ Hunter, ${ }^{4}$ Graham, ${ }^{5,6}$ Yang, ${ }^{7}$ and Ting. ${ }^{8,9}$ In recent years, a number of authors have extended the early work to the analysis of indentation measurements in viscoelastic solids. ${ }^{10-27}$

One of the widely used methods is to obtain the elastic modulus from the initial unloading stiffness or slope (Fig. 1), $S=(\mathrm{d} F / \mathrm{d} h)_{\mathrm{m}}$, of the unloading curve at the maximum indenter displacement $h_{\mathrm{m}}{ }^{28-30}$

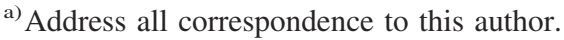

e-mail: yang.t.cheng@gm.com

This author was an editor of this journal during the review and decision stage. For the JMR policy on review and publication of manuscripts authored by editors, please refer to http://www.mrs. org/publications/jmr/policy.html.
}

DOI: $10.1557 / J M R .2005 .0389$

$$
S=\left.\frac{\mathrm{d} F}{\mathrm{~d} h}\right|_{h=h_{\mathrm{m}}}=\frac{4 G}{1-v} a=\frac{2 E}{\sqrt{\pi}\left(1-v^{2}\right)} \sqrt{A}
$$

where $G$ is the shear modulus, $E=2 G(1+v)$ is Young's modulus, $v$ is Poisson's ratio, $a$ is the contact radius, and $A=\pi a^{2}$ is the contact area. Equation (1) can be derived from the theory for elastic contacts between flat surfaces and spheres, ${ }^{31}$ flat punches, ${ }^{31}$ and conical punches. ${ }^{32}$ More generally, Sneddon has derived expressions for load, displacement, and contact depth for elastic contacts between a rigid, axisymmetric punch with an arbitrary smooth profile and an elastic half-space. ${ }^{33}$ Using Sneddon's results, Pharr et al. ${ }^{29}$ showed that Eq. (1) holds true for rigid indenters of arbitrary smooth profiles indenting elastic solids. Equation (1) has also been applied to indentation experiments where plastic deformation occurs. Doerner and $\mathrm{Nix}^{28}$ suggested that if the area in contact remains constant during initial unloading, the elastic behavior might be modeled as that of a blunt punch indenting an elastic solid. Oliver and Pharr ${ }^{30}$ pointed out that Eq. (1) can be used even when the contact area between the indenter and the solid changes continuously as the indenter is withdrawn and the indenter does not behave like a flat punch. We have recently shown that Eq. (1) is true for indentation in elastic-plastic 


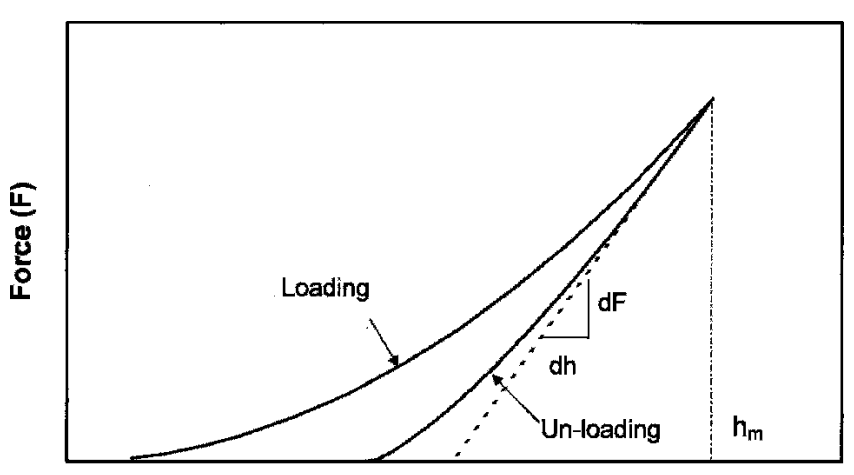

Displacement (h)

FIG. 1. Typical indentation load-displacement curve and initial unloading slope.

solids with or without work hardening and residual stress. ${ }^{34}$ However, Lu et al. ${ }^{18}$ and Kumar and Narasimhan ${ }^{19}$ have recently suggested that Eq. (1) may not be applicable to indentation in viscoelastic solids. For conical and spherical indentation in linear viscoelastic solids, we have recently shown that Eq. (1) is valid provided the unloading rate is sufficiently fast. ${ }^{24-27}$

To use Eq. (1) to determine the elastic modulus, the contact radius $a$ or contact area $A$ must be known. For a given indenter, the contact radius or area can be obtained from the contact depth $h_{\mathrm{c}}$ (see Fig. 2). The most widely used method for estimating the contact depth is the procedure proposed by Oliver and Pharr, ${ }^{29,30}$ in particular, the equation for $h_{\mathrm{c}}$ at the indenter displacement $h_{\mathrm{m}}$

$$
h_{\mathrm{c}}=h_{\mathrm{m}}-\xi \frac{F_{\mathrm{m}}}{(\mathrm{d} F / \mathrm{d} h)_{\mathrm{m}}},
$$

where $F_{\mathrm{m}}$ and $(\mathrm{d} F / \mathrm{d} h)_{\mathrm{m}}$ are the respective load and the initial slope of the unloading curve at the indenter displacement $h_{\mathrm{m}}$. The numerical values of $\xi$ are $(2 / \pi)(\pi-2)$ $=0.727$ and $3 / 4$ for conical and paraboloid revolution, respectively. Although Eq. (2) was derived from solutions to elastic contact problems, it has been used to estimate contact depth for indentation in elastic-plastic solids ${ }^{29,30}$ and viscoelastic solids. ${ }^{10,17}$ However, our recent work suggests that Eq. (2) may not be applicable for conical and spherical indentation in linear viscoelastic solids under certain loading-unloading protocols. ${ }^{25,26}$

For indentation in viscoelastic solids, it has been

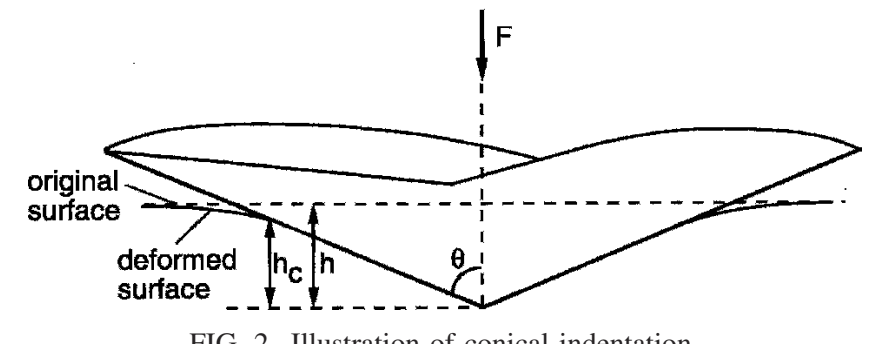

FIG. 2. Illustration of conical indentation. customary to have a "hold-at-peak-load" period between loading and unloading in load-controlled instrumented indentation measurements. This hold period is to avoid the occurrence of the "bulge" on the unloading curves, ${ }^{10,17,20-23}$ thus facilitating the determination of a meaningful unloading slope. Recently, Ngan et al. have suggested ${ }^{20-23}$ that, for load-controlled indentation measurements in a viscoelastic situation, the corrected elastic stiffness $S_{\mathrm{e}}$ can be calculated from the measured unloading stiffness $S=\mathrm{d} F / \mathrm{d} h$

$$
\frac{1}{S_{\mathrm{e}}}=\frac{1}{S}+\frac{\mathrm{d} h /\left.\mathrm{d} t\right|_{t=t_{\mathrm{m}}^{-}}}{v_{\mathrm{F}}},
$$

where $\mathrm{d} h /\left.\mathrm{d} t\right|_{t=t_{\mathrm{m}}^{-}}$is the indenter displacement rate at the end of the load hold just prior to unloading, and $\nu_{\mathrm{F}}=$ $|\mathrm{d} F / \mathrm{d} t|$ is the initial unloading rate. $S_{\mathrm{e}}$ calculated this way should replace $\mathrm{d} F / \mathrm{d} h$ in Eqs. (1) and (2) for calculating the elastic modulus and contact depth, respectively. In this work, we examine the validity of Eqs. (1)-(3) using analytical modeling and finite element calculations. Furthermore, we derive a corresponding equation for unloading slopes after a "hold-at-the-maximumdisplacement" for displacement-controlled indentation measurements. These relationships should facilitate the analysis of instrumented indentation in viscoelastic solids.

\section{DERIVATION}

\section{A. Linear viscoelastic solids}

We assume that the linear viscoelastic solid can be described by the following constitutive relationships ${ }^{35,36}$ between deviatoric stress and strain $s_{\mathrm{ij}}$ and $d_{\mathrm{ij}}$ and between dilatational stress and strain $\sigma_{\mathrm{ii}}$ and $\epsilon_{\mathrm{ii}}$

$$
\begin{aligned}
& s_{\mathrm{ij}}(t)=2 \int_{0}^{t} G(t-\tau) \frac{\partial d_{\mathrm{ij}}(\tau)}{\partial \tau} \mathrm{d} \tau, \\
& \sigma_{\mathrm{ii}}(t)=3 \int_{0}^{t} K(t-\tau) \frac{\partial \epsilon_{\mathrm{ii}}(\tau)}{\partial \tau} \mathrm{d} \tau,
\end{aligned}
$$

where $G(t)$ is the relaxation modulus in shear and $K(t)$ is the relaxation modulus in dilatation. The time-dependent Young's modulus and Poisson's ratio are then given by $E(t)=[9 K(t) G(t)] /[3 K(t)+G(t)]$ and $v(t)=[E(t) / 2 G(t)]$ -1 , respectively. Alternatively, the stress-strain relations can be written as ${ }^{35,36}$

$$
\begin{aligned}
& 2 d_{\mathrm{ij}}(t)=\int_{0}^{t} J_{\mathrm{s}}(t-\tau) \frac{\partial s_{\mathrm{ij}}(\tau)}{\partial \tau} \mathrm{d} \tau, \\
& 3 \epsilon_{\mathrm{ii}}(t)=\int_{0}^{t} J_{v}(t-\tau) \frac{\partial \sigma_{\mathrm{ii}}(\tau)}{\partial \tau} \mathrm{d} \tau,
\end{aligned}
$$

where $J_{\mathrm{s}}(t)$ is the shear compliance and $J_{\mathrm{v}}(t)$ is the volumetric compliance. $G(t)$ and $J_{\mathrm{s}}(t)$, as well as $K(t)$ and $J_{\mathrm{v}}(t)$, are related, which can be demonstrated using Laplace transformation. ${ }^{35,36}$ In the following, we assume that Poisson's ratio is time independent. As a 
result, either $G(t)$ and $v$ or $J_{\mathrm{s}}(t)$ and $v$ are sufficient to describe the linear viscoelastic behavior.

We discuss conical indentation in the main text and provide the corresponding equations for spherical indentation in the appendix since the approach and conclusions are similar for the two types of indenters.

\section{B. Conical indentation in linear viscoelastic solids: Relationships between force, displacement, and contact depth}

For a rigid, smooth, and frictionless conical indenter with half-angle $\theta$ indenting a linear viscoelastic solid with a constant Poisson's ratio and when force $F(t)$ is the independent variable, the displacement $h(t)$ is given by ${ }^{5-9,13-15,24,25}$

$$
h^{2}(t)=\frac{\pi(1-\nu)}{4 \tan \theta} \int_{0}^{t} J_{\mathrm{s}}(t-\tau) \frac{\mathrm{d} F(\tau)}{\mathrm{d} \tau} \mathrm{d} \tau
$$

When $h(t)$ is the independent variable, the force is given by

$$
F(t)=\frac{8 \tan \theta}{\pi(1-v)} \int_{0}^{t} G(t-\tau) h(\tau) \frac{\mathrm{d} h(\tau)}{\mathrm{d} \tau} \mathrm{d} \tau
$$

Under either displacement- or load-controlled indentation, the relationship between contact depth $h_{\mathrm{c}}$ and indenter displacement $h$ is given by

$$
\frac{h_{\mathrm{c}}(t)}{h(t)}=\frac{2}{\pi}
$$

Equations (6)-(8) are special cases of more general expressions derived by Graham ${ }^{5}$ and Ting. ${ }^{8}$ They suggested that Eqs. (6)-(8) are valid when the contact area is a monotonically increasing function of time. We note that Eq. (8) is exactly the same as that derived by Sneddon for conical indentation in purely elastic solids. ${ }^{33}$

\section{Conical indentation in linear viscoelastic solids: Initial unloading slopes without a holding period}

We have recently demonstrated, through analysis and finite element calculations, that Eqs. (6)-(8) can be used to analyze initial unloading after a loading period with non-decreasing functions of $h(t)$ or $F(t) .{ }^{24,25}$ Specifically, the initial unloading slopes are given by, using Eqs. (6)(8)

$$
\begin{aligned}
\left.\frac{\mathrm{d} F}{\mathrm{~d} h}\right|_{h=h_{\mathrm{m}}}= & \frac{4 h_{\mathrm{c}} \tan \theta}{1-v} \\
& \times \frac{1}{J(0)-\left.\frac{1}{\nu_{\mathrm{F}}} \int_{0}^{t_{\mathrm{m}}} \frac{\mathrm{d} J_{\mathrm{s}}(\eta)}{\mathrm{d} \eta}\right|_{\eta=t_{\mathrm{m}}-\tau} \frac{\mathrm{d} F(\tau)}{\mathrm{d} \tau} \mathrm{d} \tau}
\end{aligned}
$$

for load-controlled indentation with an initial unloading rate $v_{\mathrm{F}}=|\mathrm{d} F / \mathrm{d} t|$ and

$$
\begin{aligned}
\left.\frac{\mathrm{d} F}{\mathrm{~d} h}\right|_{h=h_{\mathrm{m}}}= & \frac{4 \tan \theta}{1-v}\left[G(0) h_{\mathrm{c}}\left(t_{\mathrm{m}}^{+}\right)\right. \\
& \left.-\left.\frac{2}{\pi \nu_{\mathrm{h}}} \int_{0}^{t_{\mathrm{m}}} \frac{\mathrm{d} G}{\mathrm{~d} \eta}\right|_{\eta=t_{\mathrm{m}}-\tau} h(\tau) \frac{\mathrm{d} h(\tau)}{\mathrm{d} \tau} \mathrm{d} \tau\right],
\end{aligned}
$$

for displacement-controlled indentation with initial unloading displacement rate $\nu_{\mathrm{h}}=|\mathrm{d} h / \mathrm{d} t|$. In deriving Eqs. (9) and (10), we assumed that Eq. (8) is valid at the moment of initial unloading. Equations (9) and (10) have been validated using finite element calculations for fast unloading after loading with monotonically increasing functions $h(t)$ or $F(t) .{ }^{24,25}$ Under fast unloading, the second terms in Eqs. (9) and (10) are negligible; these equations become the same as Eq. (1) with $G(0)=1 / J_{\mathrm{s}}(0)$ in place of $G$. Thus, the "instantaneous" properties, $G(0) /$ $(1-v)$ or $E(0) /\left(1-v^{2}\right)$, can be obtained from either displacement or load-controlled indentation measurements using Eqs. (8)-(10), provided that the unloading rate, $v_{\mathrm{h}}$ or $v_{\mathrm{F}}$, is sufficiently fast. When unloading rates are sufficiently fast, the unloading slope is no longer a function of the unloading rate. Earlier finite element calculations suggest that "sufficiently fast" unloading can be achieved when the time duration of liner unloading is about 0.1 to 0.01 times the relaxation time of linear viscoelastic materials. ${ }^{25,26}$ In practice, several indentation experiments with different unloading rates spanning several orders of magnitudes may be required to assess whether unloading rates are fast enough. It is therefore convenient to develop a technique in which an arbitrary unloading rate is sufficient to allow the determination of the instantaneous modulus. Applying a "hold" period between the loading and unloading is shown, as seen below, to provide this expediency.

\section{Conical indentation in linear viscoelastic solids: Initial unloading slopes with a holding period}

We consider a load profile shown in Fig. 3(a). It has a loading period where the force is given by an arbitrary monotonically increasing function, a "hold-at-the-peak load" period with a constant force, and an arbitrary unloading period with an initial unloading rate $\nu_{\mathrm{F}}=|\mathrm{d} F / \mathrm{d} t|$. The load profile can be described as follows for $0<t<t_{\mathrm{m}}$

$$
F(t)=\left\{\begin{array}{ll}
f(t), & 0 \leqslant t \leqslant t_{1} \\
f\left(t_{1}\right), & t_{1} \leqslant t<t_{\mathrm{m}}
\end{array},\right.
$$

where $f(t)$ is a monotonically increasing function with $f(0)=0$. Assuming that Eq. (6) is applicable up to initial unloading, we inserted Eq. (11) into Eq. (6) and obtained, after differentiation, the velocity of the indenter at $t_{\mathrm{m}}^{-}$

$$
\left.\frac{\mathrm{d} h(t)}{\mathrm{d} t}\right|_{t_{\mathrm{m}}^{-}}=\left.\frac{\pi(1-v)}{8 h\left(t_{\mathrm{m}}^{-}\right) \tan \theta} \int_{0}^{t_{1}} \frac{\partial J_{\mathrm{s}}(\eta)}{\partial \eta}\right|_{\eta=t_{\mathrm{m}}^{-}-\tau}\left[\frac{\mathrm{d} f(\tau)}{\mathrm{d} \tau}\right] \mathrm{d} \tau .
$$


$\mathrm{F}(\mathrm{t})$

(a)
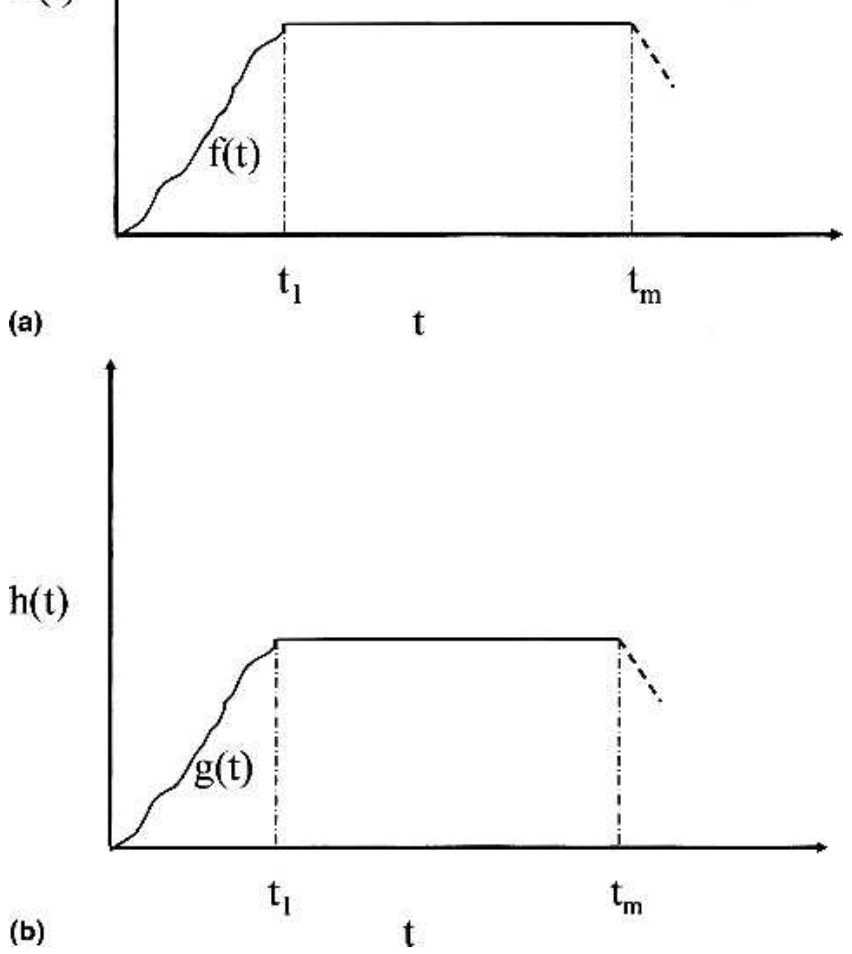

FIG. 3. Illustration of (a) a load profile for load-controlled indentation and (b) a displacement profile for displacement-controlled indentation.

Since $\mathrm{d} F(\tau) / \mathrm{d} \tau=0$ during the hold period, we obtain, using Eq. (9), the unloading slope at $t_{\mathrm{m}}^{+}$

$$
\begin{aligned}
\frac{1}{\mathrm{~d} F / \mathrm{d} h}= & \frac{(1-v)}{4 h_{\mathrm{c}} \tan \theta}\left[J_{\mathrm{s}}(0)\right. \\
& \left.-\left.\frac{1}{\nu_{\mathrm{F}}} \int_{0}^{t_{\mathrm{m}}} \frac{\mathrm{d} J_{\mathrm{s}}(\eta)}{\mathrm{d} \eta}\right|_{\eta=t_{\mathrm{m}}-\tau} \frac{\mathrm{d} F(\tau)}{\mathrm{d} \tau} \mathrm{d} \tau\right] \\
= & \frac{(1-v)}{4 h_{\mathrm{c}} \tan \theta}\left[J_{\mathrm{s}}(0)\right. \\
& \left.-\left.\frac{1}{\nu_{\mathrm{F}}} \int_{0}^{t_{1}} \frac{\mathrm{d} J_{\mathrm{s}}(\eta)}{\mathrm{d} \eta}\right|_{\eta=t_{\mathrm{m}}-\tau} \frac{\mathrm{d} F(\tau)}{\mathrm{d} \tau} \mathrm{d} \tau\right] \\
= & \frac{(1-\nu)}{4 h_{\mathrm{c}} \tan \theta} J_{\mathrm{s}}(0)-\frac{\mathrm{d} h /\left.\mathrm{d} t\right|_{t=t_{\mathrm{m}}^{-}}}{\nu_{\mathrm{F}}},
\end{aligned}
$$

where in the last step we used Eq. (12). Equation (13) can be written as

$$
\frac{(1-v)}{4 a} J_{\mathrm{s}}(0)=\frac{1}{\mathrm{~d} F / \mathrm{d} h}+\frac{\mathrm{d} h /\left.\mathrm{d} t\right|_{t=t_{\mathrm{m}}^{-}}}{v_{\mathrm{F}}}
$$

Equation (14) shows that the instantaneous properties, $G(0) /(1-v)=1 /\left[J_{\mathrm{s}}(0)(1-v)\right]$, can be obtained from the measurement of initial unloading slope $\mathrm{d} F / \mathrm{d} h$, the velocity of the indenter immediately before unloading $\mathrm{d} h /$ $\left.\mathrm{d} t\right|_{t=t_{\mathrm{m}}^{-}}$, and the rate of unloading $\nu_{\mathrm{F}}$. Equation (14) is equivalent to combining Eqs. (1) and (3), thus providing an alternative derivation of these equations first suggested by Ngan et al. ${ }^{20-23}$ Equation (14) shows that the "hold-at-the-peak-load" method provides a convenient means to use instrumented indentation under loadcontrol to determine the instantaneous modulus.

We now derive the corresponding equations for a "hold-at-the-maximum-displacement" method for indentation measurements when displacement is the independent variable. We consider a displacement profile shown in Fig. 3(b). It has a loading period where the displacement is given by an arbitrary monotonically increasing function, a hold period with a constant displacement, and an arbitrary unloading period with an initial unloading rate, $v_{\mathrm{h}}=|\mathrm{d} h / \mathrm{d} t|$. The displacement profile can be described, for $0<t<t_{\mathrm{m}}$, as

$$
h(t)=\left\{\begin{array}{ll}
g(t), & 0 \leqslant t<t_{1} \\
g\left(t_{1}\right), & t_{1} \leqslant t<t_{\mathrm{m}}
\end{array},\right.
$$

where $g(t)$ is a monotonically increasing function with $g(0)=0$. Assuming that Eq. (7) is applicable up to initial unloading, we insert Eq. (15) in Eq. (7) and obtain, after differentiation, the rate of force relaxation at $t_{\mathrm{m}}^{-}$

$$
\left.\frac{\mathrm{d} F(t)}{\mathrm{d} t}\right|_{t_{\mathrm{m}}^{-}}=\left.\frac{8 \tan \theta}{\pi(1-\nu)} \int_{0}^{t_{1}} \frac{\partial G(\eta)}{\partial \eta}\right|_{\eta=t_{\mathrm{m}}^{-} \tau} g(\tau)\left[\frac{\mathrm{d} g(\tau)}{\mathrm{d} \tau}\right] \mathrm{d} \tau .
$$

Since $\mathrm{d} h(\tau) / \mathrm{d} \tau=0$ during the hold period, we obtain using Eq. (10) the unloading slope at $t_{\mathrm{m}}^{+}$:

$$
\begin{aligned}
\left.\frac{\mathrm{d} F}{\mathrm{~d} h}\right|_{h=h_{\mathrm{m}}}= & \frac{4 \tan \theta}{1-v}\left[G(0) h_{\mathrm{c}}\left(t_{\mathrm{m}}^{+}\right)\right. \\
& \left.-\left.\frac{2}{\pi \nu_{\mathrm{h}}} \int_{0}^{t_{\mathrm{m}}} \frac{\mathrm{d} G}{\mathrm{~d} \eta}\right|_{\eta=t_{\mathrm{m}}-\tau} h(\tau) \frac{\mathrm{d} h(\tau)}{\mathrm{d} \tau} \mathrm{d} \tau\right] \\
= & \frac{4 \tan \theta}{1-v}\left[G(0) h_{\mathrm{c}}\left(t_{\mathrm{m}}^{+}\right)\right. \\
& \left.-\left.\frac{2}{\pi v_{\mathrm{h}}} \int_{0}^{t_{1}} \frac{\mathrm{d} G}{\mathrm{~d} \eta}\right|_{\eta=t_{\mathrm{m}}-\tau} g(\tau) \frac{\mathrm{d} g(\tau)}{\mathrm{d} \tau} \mathrm{d} \tau\right] \\
= & \frac{4 \tan \theta}{1-v} G(0) h_{\mathrm{c}}\left(t_{\mathrm{m}}^{+}\right)-\frac{v_{\mathrm{h}}}{t_{\mathrm{m}_{\mathrm{m}}}},
\end{aligned}
$$

where in the last step we have used Eq. (16). Equation (17) can be written as

$$
\frac{4 G(0)}{1-\nu} a=\left.\frac{\mathrm{d} F}{\mathrm{~d} h}\right|_{h=h_{\mathrm{m}}}+\frac{\mathrm{d} F /\left.\mathrm{d} t\right|_{t_{\mathrm{m}}^{-}}}{v_{\mathrm{h}}} .
$$


Equation (18) shows that $G(0) /(1-v)$ can be obtained from the measurement of initial unloading slope $\mathrm{d} F / \mathrm{d} h$, the rate of relaxation of force on the indenter immediately before unloading $\mathrm{d} F /\left.\mathrm{d} t\right|_{t=t_{\mathrm{m}}^{-}}$, and the rate of unloading $v_{\mathrm{h}}$.

The above derivations make clear the underlying assumptions, namely that the general equations, Eqs. (6)(8), are applicable up to initial unloading for either load or displacement control. However, Eqs. (6)-(8) were derived under the assumption of monotonically increasing contact area with time. Therefore, it is not obvious that the relationship between contact depth and indenter displacement, $h_{\mathrm{c}}=(2 / \pi) h$ [Eq. (8)], should be true for the hold period, especially during the "hold-at-themaximum-displacement" period. Finite element calculations are, therefore, conducted to test the validity of Eqs. (8), (14), and (18). The numerical calculations also provide an opportunity for evaluating the validity of Eqs. (2) and (3) for contact depth determination.

\section{FINITE ELEMENT ANALYSIS}

\section{A. Finite element model}

A three-parameter "standard" linear viscoelastic model with a constant Poisson's ratio is used to describe the extension relaxation modulus $E(t)=2 G(t)(1+v)$

$$
E(t)=k_{1}+k_{2} \exp \left(\frac{-t}{\tau}\right)= \begin{cases}k_{1}+k_{2}, & \text { for } t \ll \tau \\ k_{1}, & \text { for } t \gg \tau\end{cases}
$$

where $\tau$ is the relaxation time. From Eq. (19), we have $E_{0}=k_{1}+k_{2}$ and $E_{\infty}=k_{1}$ for $t=0$ and $t=\infty$, respectively. In this work, we choose a linear viscoelastic material with $E_{0}=696 \mathrm{MPa}, E_{\infty}=68.9 \mathrm{MPa}, \tau=0.99$ $\mathrm{s}$, and $v=0.4833$. Finite element calculations were carried out using the classical isotropic linear viscoelastic model implemented in ABAQUS (HKS, Inc., Pawtucket, RI) using either load or displacement as the independent variable. The finite element mesh is the same as that used in Ref. 37.

\section{B. Load-controlled conical indentation in linear viscoelastic materials}

We consider a frictionless, rigid conical indenter of half angle $\theta=70.3^{\circ}$ indenting an isotropic linear viscoelastic solid. This indenter half angle is chosen since its depth-to-volume relation is the same as that for the Berkovich indenter so that the results are expected to be applicable to Berkovich indentation.

We first investigate the relationship between the contact depth and indentation depth by considering a loadcontrol indentation with the force profile of $10 \mathrm{~s}$ loading, $2 \mathrm{~s}$ holding, and $5 \mathrm{~s}$ unloading [see Fig. 4(a)]. The maximum applied load is $273 \mu \mathrm{N}$. The load-displacement
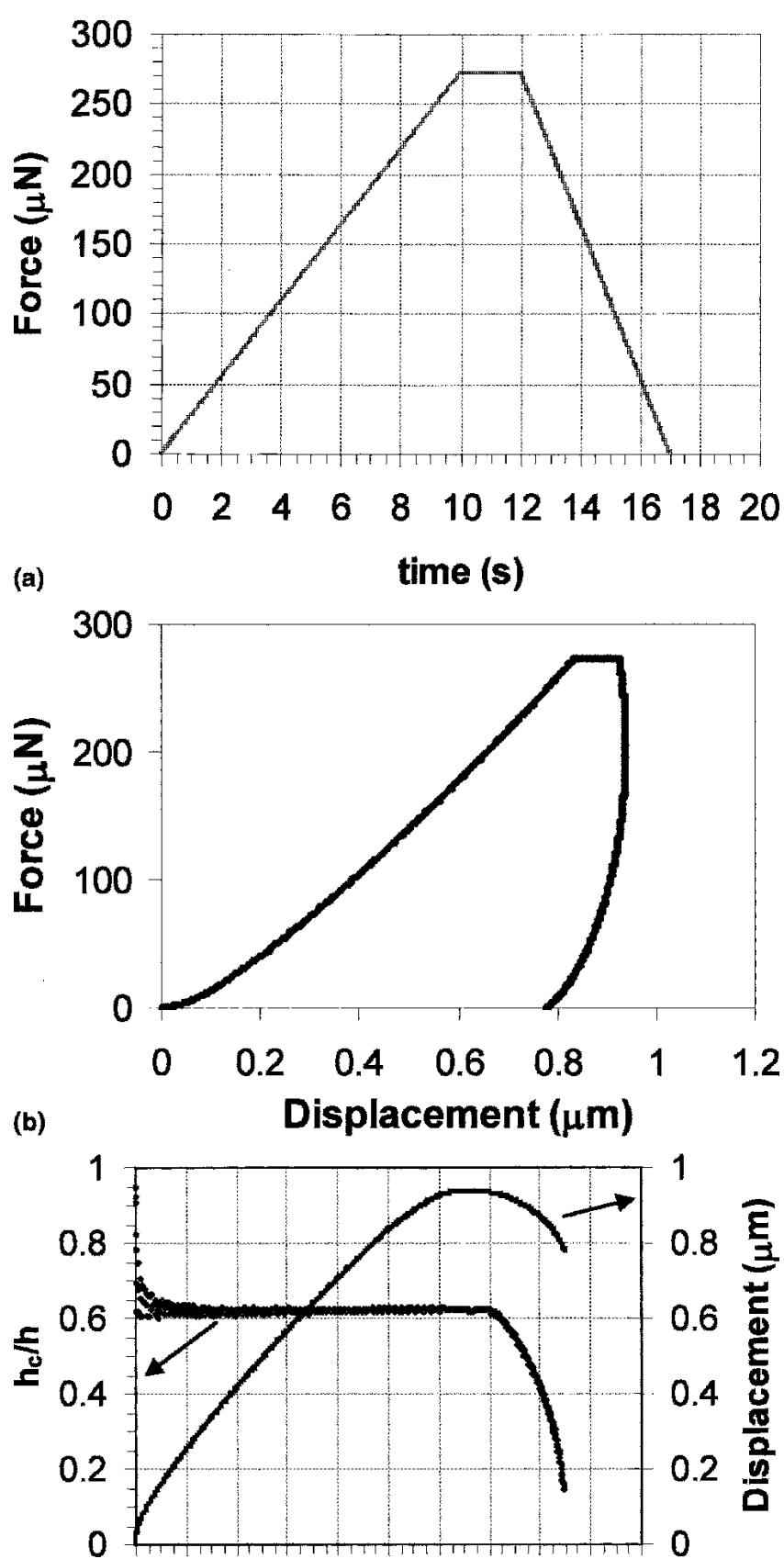

\section{$\begin{array}{lllllll}0 & 2 & 4 & 6 & 8 & 101214161820\end{array}$ Time (s)}

FIG. 4. Load-controlled conical indentation in linear viscoelastic solids: (a) force profile as the input to the finite element calculation; (b) the calculated load-displacement curve; and (c) the calculated ratio of contact depth to indenter displacement $h_{\mathrm{c}}(t) / h(t)$, and the indenter displacement $h(t)$

curve is shown in Fig. 4(b), where a "nose" appears due to the slow unloading rate. The appearance of the nose is the result of continuing forward movement of the indenter after unloading has occurred, as seen from Fig. 4(c). Although both the indenter displacement and contact depth are time dependent, Fig. 4(c) clearly shows 
TABLE I. Load-controlled conical indentation in a linear viscoelastic solid.

\begin{tabular}{|c|c|c|c|c|c|c|c|c|}
\hline Case number & $\mathrm{I}$ & II & III & IV & $\mathrm{V}$ & VI & VII & VIII \\
\hline Maximum force $F_{\max }(\mu \mathrm{N})$ & 273 & 273 & 273 & 273 & 273 & 273 & 273 & 273 \\
\hline Loading time (s) & 10 & 10 & 10 & 10 & 10 & 10 & 10 & 1 \\
\hline Hold time (s) & 0 & 0 & 5 & 2 & 2 & 10 & 1 & 5 \\
\hline Unloading, time (s) & 5 & 0.01 & 5 & 5 & 10 & 1 & 1 & 5 \\
\hline Unloading rate, $\nu_{\mathrm{F}}(\mu \mathrm{N} / \mathrm{s})$ & 54.6 & 27300 & 54.6 & 54.6 & 27.3 & 273 & 273 & 54.6 \\
\hline Apparent stiffness, $S(\mu \mathrm{N} / \mu \mathrm{m})$ & -1574 & 2913 & -5110 & -2440 & -878 & 4941 & 5977 & -1923 \\
\hline Velocity of the indenter, $\mathrm{d} h /\left.\mathrm{d} t\right|_{t=t_{\mathrm{m}}^{-}}(\mu \mathrm{m} / \mathrm{s})$ & $\ldots$ & $\cdots$ & 0.0266 & 0.0401 & 0.0401 & 0.0145 & 0.0461 & 0.0469 \\
\hline Elastic stiffness, $S_{\mathrm{e}}(\mu \mathrm{N} / \mu \mathrm{m})$ & -1574 & 2913 & 3425 & 3073 & 2933 & 3913 & 2973 & 2944 \\
\hline Contact area, $A\left(\mu \mathrm{m}^{2}\right)$ & 7.34 & 7.34 & 11.34 & 9.11 & 9.11 & 13.72 & 8.32 & 8.31 \\
\hline Calculated instantaneous modulus, $E_{0}^{\mathrm{cal}}(\mathrm{MPa})$ & -395 & 730 & 691 & 692 & 678 & 718 & 700 & 694 \\
\hline Actual instantaneous modulus, $E_{0}(\mathrm{MPa})$ & 696 & 696 & 696 & 696 & 696 & 696 & 696 & 696 \\
\hline Relative error, $\left(E_{0}^{\mathrm{cal}}-E_{0}\right) / E_{0}$ & $-157 \%$ & $4.9 \%$ & $-0.7 \%$ & $-0.6 \%$ & $-2.6 \%$ & $3.2 \%$ & $0.6 \%$ & $-0.3 \%$ \\
\hline Indentation depth, $h(\mu \mathrm{m})$ & 0.833 & 0.833 & 1.020 & 0.924 & 0.924 & 1.117 & 0.882 & 0.878 \\
\hline Contact depth by FEM, $h_{\mathrm{c}}(\mu \mathrm{m})$ & 0.516 & 0.516 & 0.635 & 0.574 & 0.573 & 0.697 & 0.548 & 0.545 \\
\hline Average $h_{\mathrm{c}} / h$ & 0.620 & 0.620 & 0.623 & 0.621 & 0.620 & 0.624 & 0.621 & 0.620 \\
\hline Contact depth by Ngan's method, $h_{\mathrm{Ngan}}(\mu \mathrm{m})$ & 0.958 & 0.765 & 0.963 & 0.861 & 0.859 & 1.067 & 0.816 & 0.811 \\
\hline
\end{tabular}

that the ratio of contact depth to indenter displacement, $h_{\mathrm{c}}(t) / h(t)$, remains a constant $(\cong 0.62)$ during the loading, holding, and initial unloading periods. Finite element method (FEM) calculations with different loading, holding, and unloading duration (see Table I) further verify that Eq. (8) is true for conical indentation in linear viscoelastic solids up to initial unloading. Therefore, the contact depth at initial unloading can be readily determined from the indentation depth using Eq. (8).

We now verify Eq. (14) using finite element calculations and the following procedure:

(i) Calculate $S_{\mathrm{e}}$ using Eq. (3) where the initial unloading rate $\nu_{\mathrm{F}}$ is the input for finite element calculations, $\mathrm{d} h /\left.\mathrm{d} t\right|_{t=t_{\mathrm{m}}}$ is the velocity of the indenter at the end of the holding period just before unloading which can be obtained from $h(t)$, and $S$ is the initial unloading stiffness from the calculated load-displacement curves.

(ii) Calculate $E_{0}^{\mathrm{cal}}$ using the contact area $A$ obtained from finite element calculations, $S_{\mathrm{e}}$, and Eq. (14) in the form of

$$
E_{0}^{\mathrm{cal}}=\frac{\sqrt{\pi}}{2} \frac{S_{\mathrm{e}}\left(1-v^{2}\right)}{\sqrt{A}}
$$

(iii) Compare $E_{0}^{\mathrm{cal}}$ with the actual instantaneous modulus $E_{0}$, used as an input parameter for the finite element calculation.

The results are summarized in Table I together with some representative load-displacement curves presented in Fig. 5. Case I in Table I shows that for indentation without a holding segment, the initial unloading stiffness is negative when the unloading rate is slow. Accordingly, a negative modulus is obtained when Eq. (1) is used, which is obviously incorrect. With increasing rate of unloading, the nose disappears. As shown in case II, Eq. (1) can be used to obtain the instantaneous modulus when $v_{\mathrm{F}}$ is very large since, according to Eq. (14), $1 / S_{\mathrm{e}} \approx 1 / S$. This finding is consistent with an earlier study of conical indentation in linear viscoelastic solids. ${ }^{24,25}$ For the indentation with a holding segment (cases III-VIII in Table I), the instantaneous modulus calculated using Eqs. (14) and (20) agrees to within $4 \%$ with the actual instantaneous modulus. Therefore, Eq. (14), which was first proposed by Ngan et al., ${ }^{20-23}$ is correct for the load-controlled conical indentation in linear viscoelastic solid. Although the finite element calculations assumed linear loading and unloading, the analytical derivation of Eq. (14) shows that we can, in practice, use a monotonically increasing loading, any duration for the holding period, and unloading with a well-defined initial unloading rate to obtain the instantaneous modulus using Eq. (14).

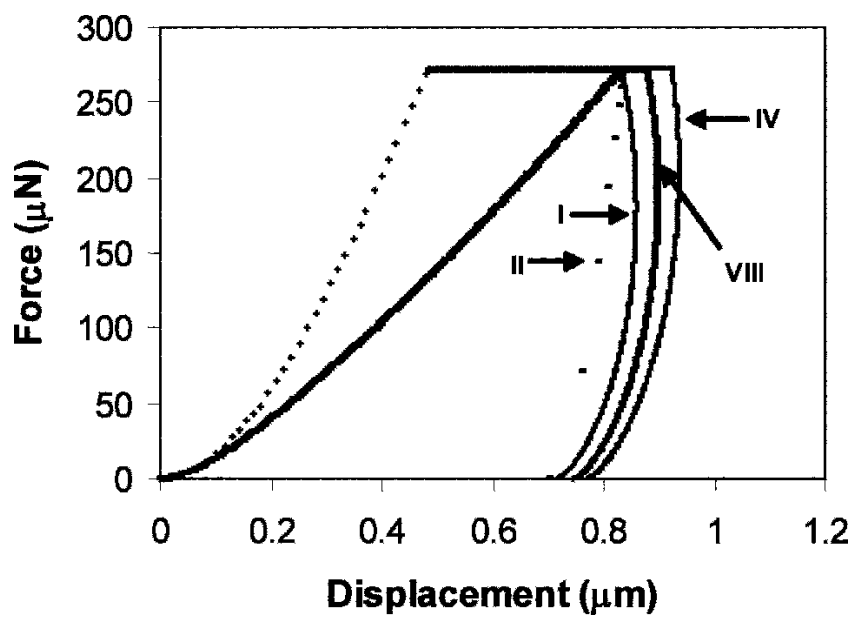

FIG. 5. Load-controlled conical indentation in linear viscoelastic solids: the calculated load-displacement curves for various loadingholding-unloading protocols. Details about each case are given in Table I. 
Ngan and his co-workers have proposed that the contact depth can be determined by replacing the $(\mathrm{d} F / \mathrm{d} h)_{\mathrm{m}}$ term in Eq. (2) with the corrected stiffness $\left(S_{\mathrm{e}}\right)$. $^{20-23}$ The contact depth so determined $\left(h_{\mathrm{Ngan}}\right)$ is compared with the contact depth obtained directly from finite element calculations $\left(h_{\mathrm{c}}\right)$, and both are shown in Table I. Obviously, there are considerable discrepancies between the $h_{\mathrm{Ngan}}$ and $h_{\mathrm{c}}$, which show that contact depth cannot be determined using Eq. (2) with the corrected stiffness. However, the contact depth can be determined using the simple relation given in Eq. (8), i.e., $h_{\mathrm{c}} / h=2 / \pi$ for ideally sharp conical indenters.

\section{Displacement-controlled conical indentation in linear viscoelastic materials}

We first study the contact depth for the displacementcontrolled conical indentation in linear viscoelastic solids with the displacement profile of $10 \mathrm{~s}$ loading, $2 \mathrm{~s}$ holding, 5 s unloading [see Fig. 6(a)]. The maximum indenter displacement is $1 \mu \mathrm{m}$. Figure 6(b) presents the calculated load-displacement curve for this displacement history. Figure 6(c) shows the dependence of indentation force $(F)$ and the ratio of contact depth to indentation depth $h_{\mathrm{c}}(t) / h(t)$ as a function of time. Figure 6(c) shows that the force decreases when the indenter position is held constant, as expected from stress relaxation. The calculations also show that $h_{\mathrm{c}}(t) / h(t)$ is a constant $(\approx 0.62)$ during the loading and holding and at the moment of initial unloading.

This seemingly unintuitive result that, for the displacement-controlled indentation, the contact depth does not change when the indenter is held at a fixed depth may be understood by considering the holding period as a second loading period with an infinitesimally small positive indenter displacement rate. During this period, $h_{\mathrm{c}}(t) / h(t)$ is expected to be a constant since the displacement is an increasing function of time. We can also conduct a thought experiment where a very slow loading rate is used such that the material behaves approximately as a purely elastic solid with a modulus given by $E_{\infty}$. The $h_{\mathrm{c}}(t) / h(t)$ is a constant for both the loading and holding for elastic solids. FEM results also show, as seen from Fig. 6(c), that Eq. (8) does not apply to the entire unloading period. In fact, $h_{\mathrm{c}}(t) / h(t)$ decreases with time. Nevertheless, these results confirm that Eq. (8) can be used to obtain the contact depth for the loading and holding periods, as well as at the point of initial unloading for displacement-controlled conical indentation in linear viscoelastic solids.

We now verify Eq. (18) using finite element calculations. Equation (18) can be rewritten as

$$
S_{\mathrm{e}}=S+\frac{\mathrm{d} F /\left.\mathrm{d} t\right|_{t_{\mathrm{m}}^{-}} ^{-}}{v_{\mathrm{h}}}
$$
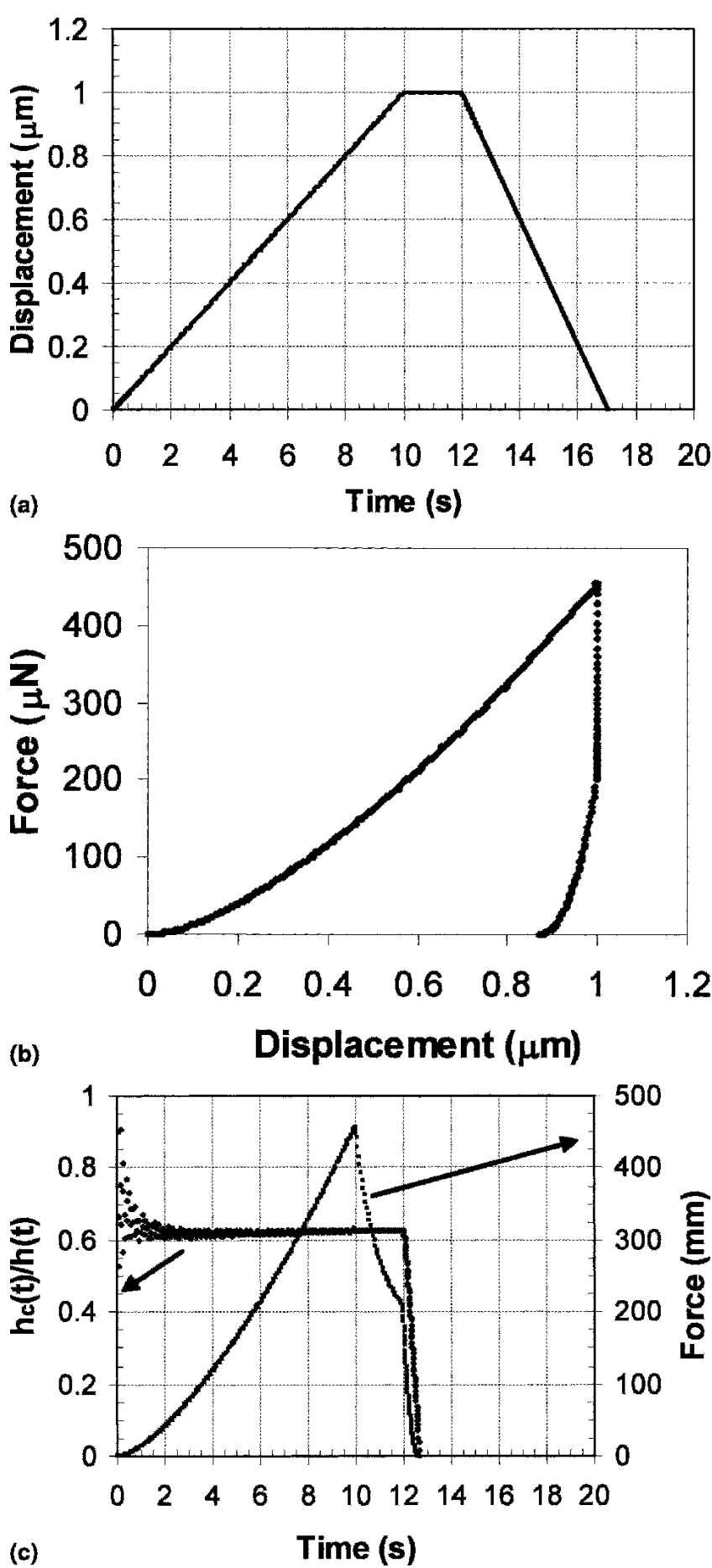

FIG. 6. Displacement-controlled conical indentation in linear viscoelastic solids: (a) displacement profile as the input to the finite element calculation; (b) the calculated load-displacement curve; and (c) the calculated ratio of contact depth to indenter displacement $h_{\mathrm{c}}(t) /$ $h(t)$, and the indentation force $F(t)$.

where

$$
S_{\mathrm{e}}=\frac{4 G(0)}{1-v} a=\frac{2 E(0)}{\sqrt{\pi}\left(1-v^{2}\right)} \sqrt{A} .
$$


TABLE II. Displacement-controlled conical indentation in a linear viscoelastic solid.

\begin{tabular}{|c|c|c|c|c|c|c|c|c|}
\hline Case number & $\mathrm{I}$ & II & III & IV & $\mathrm{V}$ & VI & VII & VIII \\
\hline Maximum displacement, $h_{\max }(\mu \mathrm{m})$ & 1 & 1 & 1 & 1 & 1 & 1 & 1 & 1 \\
\hline Loading time (s) & 10 & 10 & 10 & 10 & 10 & 10 & 10 & 1 \\
\hline Hold time (s) & 0 & 0 & 5 & 2 & 2 & 10 & 1 & 5 \\
\hline Unloading, time (s) & 5 & 0.01 & 5 & 5 & 10 & 1 & 1 & 5 \\
\hline Unloading rate, $\nu_{\mathrm{h}}(\mu \mathrm{m} / \mathrm{s})$ & 0.2 & 100 & 0.2 & 0.2 & 0.1 & 1 & 1 & 0.2 \\
\hline Apparent stiffness, $S(\mu \mathrm{N} / \mu \mathrm{m})$ & 4945 & 3508 & 3549 & 3737 & 3925 & 3523 & 3652 & 3570 \\
\hline Force relaxation rate, $\mathrm{d} F /\left.\mathrm{d} t\right|_{t_{\mathrm{m}}^{-}}(\mu \mathrm{N} / \mathrm{s})$ & $\cdots$ & $\cdots$ & -2.18 & -44.4 & -44.4 & -0.040 & -122 & -8.70 \\
\hline Elastic stiffness, $S_{\mathrm{e}}(\mu \mathrm{N} / \mu \mathrm{m})$ & 4945 & 3508 & 3538 & 3515 & 3480 & 3523 & 3530 & 3526 \\
\hline Contact area, $A\left(\mu \mathrm{m}^{2}\right)$ & 10.78 & 10.78 & 10.73 & 10.76 & 10.76 & 10.71 & 10.76 & 10.69 \\
\hline Calculated instantaneous modulus, $E_{0}^{\mathrm{cal}}(\mathrm{MPa})$ & 1023 & 726 & 734 & 728 & 721 & 731 & 731 & 733 \\
\hline Actual instantaneous modulus, $E_{0}(\mathrm{MPa})$ & 696 & 696 & 696 & 696 & 696 & 696 & 696 & 696 \\
\hline Relative error, $\left(E_{0}^{\mathrm{cal}}-E_{0}\right) / E_{0}$ & $47 \%$ & $4.3 \%$ & $5.4 \%$ & $4.6 \%$ & $3.6 \%$ & $5.1 \%$ & $5.0 \%$ & $5.2 \%$ \\
\hline Contact depth by FEM, $h_{\mathrm{c}}(\mu \mathrm{m})$ & 0.624 & 0.624 & 0.623 & 0.624 & 0.624 & 0.622 & 0.624 & 0.622 \\
\hline Average $h_{\mathrm{c}} / h$ & 0.621 & 0.621 & 0.622 & 0.622 & 0.622 & 0.622 & 0.621 & 0.622 \\
\hline Force at unloading, $F_{\max }(\mu \mathrm{N})$ & 456 & 456 & 174 & 210 & 210 & 172 & 276 & 179 \\
\hline Contact depth by Ngan's method, $h_{\mathrm{Ngan}}(\mu \mathrm{m})$ & 0.933 & 0.905 & 0.964 & 0.957 & 0.956 & 0.965 & 0.943 & 0.963 \\
\hline
\end{tabular}

Since $\nu_{\mathrm{h}}$ is specified and $S=\mathrm{d} F /\left.\mathrm{d} h\right|_{h=h_{\mathrm{m}}}, \mathrm{d} F /\left.\mathrm{d} t\right|_{t=t_{\mathrm{m}}^{-}}$, and the contact area $A$ can be obtained from finite element calculations, the instantaneous modulus $E_{0}^{\text {cal }}$ can then be obtained from Eq. (22) and be compared with the actual instantaneous modulus $E_{0}$, used as an input parameter for the finite element calculations. Table II summarizes the results for displacement-controlled indentation with various loading, holding, and unloading period, and Fig. 7 shows several representative load-displacement curves. Cases I and II in Table II show that when there is no holding segment, the smaller the unloading rate, the larger the deviation from the actual instantaneous modulus. However, for the indentation with a hold segment, after correcting the stiffness using Eq. (21), the instantaneous modulus calculated using Eq. (22) agrees well with the actual value. Thus, Eq. (18) is valid for

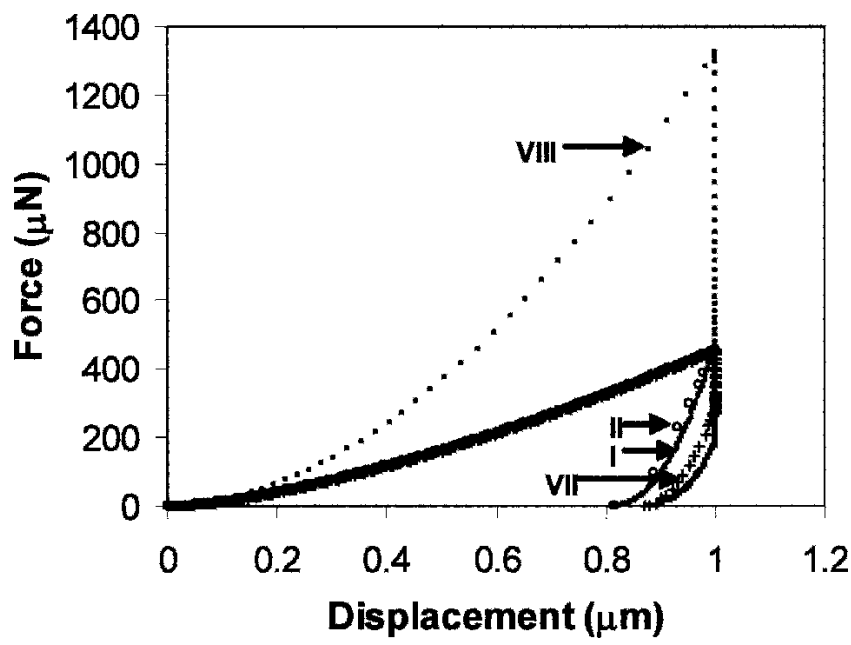

FIG. 7. Displacement-controlled conical indentation in linear viscoelastic solids: load-displacement curves for various loadingholding-unloading protocols. Details about each case are shown in Table II. displacement-controlled conical indentation in linear viscoelastic solids. Furthermore, the data in Table II show that the method proposed by Ngan et al. ${ }^{20-23}$ for determining contact depth is incorrect for the displacementcontrolled conical indentations. Similar results are given in the Appendix for spherical indentation in linear viscoelastic solids.

\section{CONCLUSIONS}

Using analytical and numerical modeling, we examined the relationships between initial unloading slope, contact depth, and the instantaneous elastic modulus for instrumented indentation in linear viscoelastic solids using either conical or spherical indenters. In particular, we studied the effects of "hold-at-the-peak-load" and "holdat-the-maximum-displacement" on initial unloading slopes and contact depths. For load-controlled indentations, we verified the relationship first proposed by Ngan et al., Eq. (14). For displacement-controlled indentations, we derived and verified a new relationship, Eq. (18). These relationships, together with the relationships between contact depth and indenter displacement, Eqs. (8) and $(8 \mathrm{~A})$, for the respective conical and spherical indenters, allow the determination of the instantaneous elastic modulus of viscoelastic solids. We also showed that the Oliver-Pharr method with or without the correction by Ngan et al. is not applicable to indentation in viscoelastic solids.

We re-emphasize that the above conclusions are based on the assumption that the material under consideration is linear viscoelastic during the entire duration of the deformation, from the initial loading, to holding at either the peak load or displacement, and to the onset of the unloading. The applicability of Eqs. (8), (14), and (18) to more general cases, such as power-law creep 
and plasticity, is beyond the scope of this work. However, we note that the earlier derivation of Eq. (3) by Ngan et al. ${ }^{20,23}$ requires only that the material obeys the viscoelastic law momentarily just before and just after the onset of the unloading process, and not necessarily during the preceding loading and holding processes. Furthermore, Ngan et al. have shown that Eq. (3) is applicable to power-law viscoelastic material, while Eq. (2) is an approximation. ${ }^{23}$ These results should therefore help us understand and facilitate the analysis of instrumented indentation measurements in linear viscoelastic solids.

\section{ACKNOWLEDGMENTS}

The authors would like to thank Mike Lukitsch, Yue Qi, Tom Perry, Wes Capehart, Lou Hector, and Mark W. Verbrugge for valuable discussions. C-M. Cheng would like to acknowledge partial support from the National Science Foundation of China, Project No. 10372101.

\section{REFERENCES}

1. E.H. Lee: Stress analysis in visco-elastic bodies. Quarterly Appl. Math. 13, 183 (1955).

2. J.R.M. Radok: Visco-elastic stress analysis. Quarterly Appl. Math. 15, 198 (1957).

3. E.H. Lee and J.R.M. Radok: The contact problem for viscoelastic bodies. J. Appl. Mech. 27, 438 (1960).

4. S.C. Hunter: The Hertz problem for a rigid spherical indenter and a viscoelastic half-space. J. Mech. Phys. Solids 8, 219 (1960).

5. G.A.C. Graham: The contact problem in the linear theory of viscoelasticity. Int. J. Eng. Sci. 3, 27 (1965).

6. G.A.C. Graham: Contact problem in linear theory of viscoelsticity when time dependent contact area has any number of maxima and minima. Int. J. Eng. Sci. 5, 495 (1967).

7. W.H. Yang: Contact problem for viscoelastic bodies. J. Appl. Mech. 33, 395 (1966).

8. T.C.T. Ting: Contact stresses between a rigid indenter and a viscoelastic half-space. J. Appl. Mech. 33, 845 (1966).

9. T.C.T. Ting: Contact problems in linear theory of viscoelasticity. J. Appl. Mech. 35, 248 (1968).

10. B.J. Briscoe, L. Fiori, and E. Pelillo: Nano-indentation of polymeric surfaces. J. Phys. D, Appl. Phys. 31, 2395 (1998).

11. P-L. Larrson and S. Carlsson: On microindentation of viscoelastic polymers. Polym. Testing 17, 49 (1998).

12. L. Cheng, X. Xia, W. Yu, L.E. Scriven, and W.W. Gerberich: Flat-punch indentation of viscoelastic material. J. Polym. Sci. B, Polym. Phys. 38, 10 (2001).

13. S. Shimizu, T. Yanagimoto, and M. Sakai: Pyramidal indentation load-depth curve of viscoelastic materials. J. Mater. Res. 14, 4075 (1999).

14. M. Sakai and S. Shimizu: Indentation rheometry for glass-forming materials. J. Non-Cryst. Solids 282, 236 (2001).

15. M. Sakai: Time-dependent viscoelastic relation between load and penetration for an axisymmetric indenter. Philos. Mag. A82, 1841 (2002).
16. M.L. Oyen and R.F. Cook: Load-displacement behavior during sharp indentation of viscous-elastic-plastic materials. J. Mater. Res. 18, 139 (2003).

17. M.R. VanLandingham: Review of instrumented indentation. J. Res. Nat. Inst. Stand. Technol. 108, 249 (2003).

18. H. Lu, B. Wang, J. Ma, G. Huang, and H. Viswanathan: Measurement of creep compliance of solid polymers by nanoindentation. Mech. Time-Dependent Mater. 7, 189 (2003).

19. M.V.R. Kumar and R. Narasimhan: Analysis of spherical indentation of linear viscoelastic materials. Curr. Sci. 87, 1088 (2004).

20. G. Feng and A.H.W. Ngan: Effects of creep and thermal drift on modulus measurement using depth-sensing indentation. J. Mater. Res. 17, 660 (2002).

21. A.H.W. Ngan and B. Tang: Viscoelastic effects during unloading in depth-sensing indentation. J. Mater. Res. 17, 2604 (2002).

22. B. Tang and A.H.W. Ngan: Accurate measurement of tip-sample contact size during nanoindentation of viscoelastic materials. J. Mater. Res. 18, 1141 (2003).

23. A.H.W. Ngan, H.T. Wang, B. Tang, and K.Y. Sze: Correcting power-law viscoelastic effects in elastic modulus measurement using depth-sensing indentation. Int. J. Solids Struct. 42, 1831 (2005).

24. Y-T. Cheng and C-M. Cheng: Scaling, dimensional analysis, and indentation measurements. Mater. Sci. Eng. R44, 91 (2004).

25. Y-T. Cheng and C-M. Cheng: Relationships between initial unloading slope, contact depth, and mechanical properties for conical indentation in linear viscoelastic solids. J. Mater. Res. 20, 1046 (2005).

26. Y-T. Cheng and C-M. Cheng: Relationships between initial unloading slope, contact depth, and mechanical properties for spherical indentation in linear viscoelastic solids. Mater. Sci. Eng., A (in press).

27. Y-T. Cheng and C-M. Cheng: A general relationship between contact stiffness, contact depth, and mechanical properties for indentation in linear viscoelastic solids using axisymmetric indenters of arbitrary profiles. Appl. Phys. Lett. 87, 111914 (2005).

28. M.F. Doerner and W.D. Nix: A method for interpreting the data from depth-sensing indentation instruments. J. Mater. Res. 1, 601 (1986).

29. G.M. Pharr, W.C. Oliver, and F.R. Brotzen: On the generality of the relationship between contact stiffness, contact area, and elastic modulus during indentation. J. Mater. Res. 7, 613 (1992).

30. W.C. Oliver and G.M. Pharr: An improved technique for determining hardness and elastic modulus using load and displacement sensing indentation experiments. J. Mater. Res. 7, 1564 (1992).

31. S.P. Timoshenko and J.N. Goodier: Theory of Elasticity, 3rd ed. (McGraw-Hill, New York, 1970).

32. A.E.H. Love: Boussinesq's problem for a rigid cone. Quart. J. Math. 10, 161 (1939).

33. I.N. Sneddon: The relation between load and penetration in the axisymmetric Boussinesq problem for a punch of arbitrary profile. Int. J. Eng. Sci. 3, 47 (1965).

34. C-M. Cheng and Y-T. Cheng: On the initial unloading slope in indentation of elastic-plastic solids by an indenter with an axisymmetric smooth profile. Appl. Phys. Lett. 71, 2623 (1997).

35. W.N. Findley, J.S. Lai, and K. Onaran: Creep and Relaxation of Nonlinear Viscoelastic Materials (Dover, New York, 1976).

36. G.T. Mase and G.E. Mase: Continuum Mechanics for Engineers, 2nd ed. (CRC, Boca Raton, FL, 1999).

37. W. Ni, Y-T. Cheng, C-M. Cheng, and D.S. Grummon: An energy based method for analyzing instrumented spherical indentation experiments. J. Mater. Res. 19, 149 (2004). 


\section{APPENDIX: ANALYSIS OF SPHERICAL INDENTATION IN LINEAR VISCOELASTIC SOLIDS USING EITHER FORCE OR DISPLACEMENT AS THE INDEPENDENT VARIABLE}

We take the same approach as that used in the main text for conical indentation. The corresponding equations are numbered Eq. $(x)$ and Eq. $(x \mathrm{~A})$ for the conical and spherical indentations, respectively. In the "classical spherical" indenter approximation, where the indenter shape is a paraboloid of revolution, the displacement $h(t)$ is given by ${ }^{1-9}$

$$
h^{3 / 2}(t)=\frac{3(1-v)}{8 \sqrt{R}} \int_{0}^{t} J_{\mathrm{s}}(t-\tau) \frac{\mathrm{d} F(\tau)}{\mathrm{d} \tau} \mathrm{d} \tau
$$

when force $F(t)$ is the independent variable. When displacement $h(t)$ is the independent variable, the force $F(t)$ is given by ${ }^{1-9}$

$$
F(t)=\frac{8 \sqrt{R}}{3(1-v)} \int_{0}^{t} G(t-\tau) \frac{\mathrm{d} h^{3 / 2}(\tau)}{\mathrm{d} \tau} \mathrm{d} \tau
$$

The relationship between contact depth $h_{\mathrm{c}}(t)$, contact radius $a(t)$, and indenter displacement $h(t)$ is the same as that in the purely elastic case $\mathrm{e}^{5,8}$

$$
h(t)=\frac{a^{2}(t)}{R}=2 h_{\mathrm{c}}(t)
$$

The expression for the initial unloading slopes when force is the independent variable is given by ${ }^{26}$

$$
\frac{\mathrm{d} F}{\mathrm{~d} h}=\frac{4 \sqrt{R h}}{(1-v)} \frac{1}{J_{\mathrm{s}}(0)-\left.\frac{1}{\nu_{\mathrm{F}}} \int_{0}^{t_{\mathrm{m}}} \frac{\mathrm{d} J_{\mathrm{s}}(\eta)}{\mathrm{d} \eta}\right|_{\eta=t_{\mathrm{m}}-\tau} \frac{\mathrm{d} F(\tau)}{\mathrm{d} \tau} \mathrm{d} \tau},
$$

and that when displacement is the independent variable is given by ${ }^{26}$

$$
\begin{aligned}
\frac{\mathrm{d} F}{\mathrm{~d} h}= & \frac{8 \sqrt{R}}{3(1-\nu)}\left[\frac{3}{2} G(0) h^{1 / 2}\left(t_{\mathrm{m}}^{+}\right)\right. \\
& \left.-\left.\frac{1}{v_{\mathrm{h}}} \int_{0}^{t_{\mathrm{m}}} \frac{\mathrm{d} G}{\mathrm{~d} \eta}\right|_{\eta=t_{\mathrm{m}}-\tau} \frac{\mathrm{d} h^{3 / 2}(\tau)}{\mathrm{d} \tau} \mathrm{d} \tau\right] .
\end{aligned}
$$

For the load profile shown in Fig. 3(a), the velocity of the indenter at $t_{\mathrm{m}}^{-}$is

$$
\left.\frac{\mathrm{d} h(t)}{\mathrm{d} t}\right|_{t_{\mathrm{m}}^{-}}=\left.\frac{1-v}{4 \sqrt{R h\left(t_{\mathrm{m}}^{-}\right)}} \int_{0}^{t_{1}} \frac{\partial J_{\mathrm{s}}(\eta)}{\partial \eta}\right|_{\eta=t_{\mathrm{m}}^{-}-\tau}\left[\frac{\mathrm{d} f(\tau)}{\mathrm{d} \tau}\right] \mathrm{d} \tau .
$$

Since $\mathrm{d} F(\tau) / \mathrm{d} \tau=0$ during the hold period, we obtain the unloading slope at $t_{\mathrm{m}}^{+}$using Eq. (9A)

$$
\begin{aligned}
\frac{1}{\mathrm{~d} F / \mathrm{d} h}= & \frac{(1-v)}{4 \sqrt{R h}}\left[J_{\mathrm{s}}(0)-\left.\frac{1}{v_{\mathrm{F}}} \int_{0}^{t_{\mathrm{m}}} \frac{\mathrm{d} J_{\mathrm{s}}(\eta)}{\mathrm{d} \eta}\right|_{\eta=t_{\mathrm{m}}-\tau} \frac{\mathrm{d} F(\tau)}{\mathrm{d} \tau} \mathrm{d} \tau\right] \\
= & \frac{(1-v)}{4 \sqrt{R h}} J_{\mathrm{s}}(0) \\
& -\left.\frac{(1-v)}{4 \sqrt{R h}} \frac{1}{\nu_{\mathrm{F}}} \int_{0}^{t_{1}} \frac{\mathrm{d} J_{\mathrm{s}}(\eta)}{\mathrm{d} \eta}\right|_{\eta=t_{\mathrm{m}}-\tau} \frac{\mathrm{d} f(\tau)}{\mathrm{d} \tau} \mathrm{d} \tau \\
= & \frac{(1-v)}{4 a} J_{\mathrm{s}}(0)-\frac{\mathrm{d} h / \mathrm{d} t_{t=t_{\mathrm{m}}^{-}}}{\nu_{\mathrm{F}}},
\end{aligned}
$$

where in the last step we used Eqs. (8A) and (12A). Equation (13A) can be written in the same form as Eq. (14).

For the displacement profile shown in Fig. 3(b), the rate of force relaxation at $t_{\mathrm{m}}^{-}$is

$$
\left.\frac{\mathrm{d} F(t)}{\mathrm{d} t}\right|_{t_{\mathrm{m}}^{-}}=\left.\frac{4 \sqrt{R}}{1-v} \int_{0}^{t_{1}} \frac{\partial G(\eta)}{\partial \eta}\right|_{\eta=t_{\mathrm{m}}^{-}-\tau} g^{1 / 2}(\tau)\left[\frac{\mathrm{d} g(\tau)}{\mathrm{d} \tau}\right] \mathrm{d} \tau \text {. }
$$

Since $\mathrm{d} h(\tau) / \mathrm{d} \tau=0$ during the hold period, we obtain, using Eq. (10A), the unloading slope at $t_{\mathrm{m}}^{+}$

$$
\begin{aligned}
\frac{\mathrm{d} F}{\mathrm{~d} h}= & \frac{8 \sqrt{R}}{3(1-v)}\left[\frac{3}{2} G(0) h^{1 / 2}\left(t_{\mathrm{m}}^{+}\right)\right. \\
& \left.-\left.\frac{1}{v_{\mathrm{h}}} \int_{0}^{t_{\mathrm{m}}} \frac{\mathrm{d} G(\eta)}{\mathrm{d} \eta}\right|_{\eta=t_{\mathrm{m}}-\tau} \frac{\mathrm{d} h^{3 / 2}(\tau)}{\mathrm{d} \tau} \mathrm{d} \tau\right] \\
= & \frac{4 \sqrt{R h}}{(1-v)} G(0) \\
& -\left.\frac{8 \sqrt{R}}{3(1-v)} \frac{1}{\nu_{\mathrm{h}}} \int_{0}^{t_{1}} \frac{\mathrm{d} G}{\mathrm{~d} \eta}\right|_{\eta=t_{\mathrm{m}}-\tau} \frac{\mathrm{d} h^{3 / 2}(\tau)}{\mathrm{d} \tau} \mathrm{d} \tau \\
= & \frac{4 a}{(1-v)} G(0)-\frac{\mathrm{d} F /\left.\mathrm{d} t\right|_{t=t_{\mathrm{m}}^{-}}}{\nu_{\mathrm{h}}},
\end{aligned}
$$

where, in the last step, we used Eqs. (8A) and (16A). Equation (17A) can be written in the same form as Eq. (18).

Finite element calculations are used to verify Eqs. (8A), (13A), and (17A) for a frictionless, spherical indenter of radius $R=2 \mu \mathrm{m}$ indenting the same isotropic, three-parameter "standard" linear viscoelastic model solid used for the conical indentation calculations. The FEM results show that, for the load-controlled and the displacement-controlled indentation, the ratio of contact depth to indentation depth is a constant $(\sim 0.52)$ during the loading, holding, and at the moment of initial unloading (see Tables IA and IIA). These results confirm that Eqs. (8A), (14), and (18) can be used to obtain the instantaneous modulus for load-controlled and displacement-controlled spherical indentation, respectively. 
TABLE IA. Load-controlled indentation in a linear viscoelastic solid using a spherical indenter of $2 \mu \mathrm{m}$ radius.

\begin{tabular}{|c|c|c|c|c|c|c|c|c|}
\hline Case number & I & II & III & IV & $\mathrm{V}$ & VI & VII & VIII \\
\hline Maximum force, $F_{\max }(\mu \mathrm{N})$ & 273 & 273 & 273 & 273 & 273 & 273 & 273 & 273 \\
\hline Loading time (s) & 10 & 10 & 10 & 10 & 10 & 10 & 10 & 1 \\
\hline Hold time (s) & 0 & 0 & 5 & 2 & 2 & 10 & 1 & 5 \\
\hline Unloading time, $(\mathrm{s})$ & 5 & 0.01 & 5 & 5 & 10 & 1 & 1 & 5 \\
\hline Unloading rate, $\nu_{\mathrm{F}}(\mu \mathrm{N} / \mathrm{s})$ & 54.6 & 27300 & 54.6 & 54.6 & 27.3 & 273 & 273 & 54.6 \\
\hline Apparent stiffness, $S(\mu \mathrm{N} / \mu \mathrm{m})$ & -1197 & 2220 & -3615 & -1772 & -635 & 3243 & 4711 & -1429 \\
\hline Velocity of the indenter, $\mathrm{d} h /\left.\mathrm{d} t\right|_{t=t_{\mathrm{m}}^{-}}(\mu \mathrm{m} / \mathrm{s})$ & $\cdots$ & $\cdots$ & 0.0381 & 0.0548 & 0.0548 & 0.0219 & 0.0619 & 0.0625 \\
\hline Elastic stiffness, $S_{\mathrm{e}}(\mu \mathrm{N} / \mu \mathrm{m})$ & -1197 & 2220 & 2370 & 2271 & 2296 & 2573 & 2277 & 2241 \\
\hline Contact area, $A\left(\mu \mathrm{m}^{2}\right)$ & 4.59 & 4.59 & 5.98 & 5.19 & 5.19 & 6.63 & 4.97 & 4.95 \\
\hline Calculated instantaneous modulus, $E_{0}^{\mathrm{cal}}(\mathrm{MPa})$ & -380 & 704 & 658 & 677 & 685 & 679 & 694 & 684 \\
\hline Actual instantaneous modulus, $E_{0}(\mathrm{MPa})$ & 696 & 696 & 696 & 696 & 696 & 696 & 696 & 696 \\
\hline Relative error, $\left(E_{0}^{\text {cal }}-E_{0}\right) / E_{0}$ & $-155 \%$ & $1.1 \%$ & $-5.4 \%$ & $-2.7 \%$ & $-1.6 \%$ & $-2.5 \%$ & $-0.3 \%$ & $-1.7 \%$ \\
\hline Indentation depth, $h(\mu \mathrm{m})$ & 0.783 & 0.783 & 1.042 & 0.906 & 0.906 & 1.186 & 0.849 & 0.843 \\
\hline Contact depth by FEM, $h_{\mathrm{c}}(\mu \mathrm{m})$ & 0.406 & 0.406 & 0.552 & 0.467 & 0.467 & 0.625 & 0.445 & 0.443 \\
\hline Average $h_{\mathrm{c}} / h$ & 0.521 & 0.521 & 0.521 & 0.521 & 0.521 & 0.522 & 0.521 & 0.520 \\
\hline Contact depth by Ngan's method, $h_{\text {Ngan }}(\mu \mathrm{m})$ & 0.954 & 0.691 & 0.956 & 0.816 & 0.817 & 1.106 & 0.759 & 0.751 \\
\hline
\end{tabular}

TABLE IIA. Displacement-controlled indentation in a linear viscoelastic solid using a spherical indenter of $2 \mu \mathrm{m}$ radius.

\begin{tabular}{|c|c|c|c|c|c|c|c|c|}
\hline Case number & I & II & III & IV & $\mathrm{V}$ & VI & VII & VIII \\
\hline Maximum displacement, $h_{\max }(\mu \mathrm{m})$ & 1 & 1 & 1 & 1 & 1 & 1 & 1 & 1 \\
\hline Loading time (s) & 10 & 10 & 10 & 10 & 10 & 10 & 10 & 1 \\
\hline Hold time (s) & 0 & 0 & 5 & 2 & 2 & 10 & 1 & 5 \\
\hline Unloading, time (s) & 5 & 0.01 & 5 & 5 & 10 & 1 & 1 & 5 \\
\hline Unloading rate, $\nu_{\mathrm{h}}(\mu \mathrm{m} / \mathrm{s})$ & 0.2 & 100 & 0.2 & 0.2 & 0.1 & 1 & 1 & 0.2 \\
\hline Apparent stiffness, $S(\mu \mathrm{N} / \mu \mathrm{m})$ & 3501 & 2425 & 2436 & 2571 & 2717 & 2429 & 2524 & 2456 \\
\hline Force relaxation rate, $\mathrm{d} F /\left.\mathrm{d} t\right|_{t_{\mathrm{m}}^{-}}(\mu \mathrm{N} / \mathrm{s})$ & $\ldots$ & $\ldots$ & -1.70 & -31.72 & -31.72 & -0.068 & -91.58 & -8.20 \\
\hline Elastic stiffness, $S_{\mathrm{e}}(\mu \mathrm{N} / \mu \mathrm{m})$ & 3501 & 2425 & 2427 & 2412 & 2400 & 2429 & 2432 & 2415 \\
\hline Contact area, $A\left(\mu \mathrm{m}^{2}\right)$ & 5.79 & 5.79 & 5.73 & 5.76 & 5.76 & 5.70 & 5.77 & 5.67 \\
\hline Calculated instantaneous modulus, $E_{0}^{\mathrm{cal}}(\mathrm{MPa})$ & 989 & 685 & 689 & 683 & 679 & 691 & 688 & 689 \\
\hline Actual instantaneous modulus, $E_{0}(\mathrm{MPa})$ & 696 & 696 & 696 & 696 & 696 & 696 & 696 & 696 \\
\hline Relative error, $\left(E_{0}^{\text {cal }}-E_{0}\right) / E_{0}$ & $42 \%$ & $-1.6 \%$ & $-1.0 \%$ & $-1.9 \%$ & $-2.4 \%$ & $-0.7 \%$ & $-1.2 \%$ & $-1.0 \%$ \\
\hline Contact depth by FEM, $h_{\mathrm{c}}(\mu \mathrm{m})$ & 0.531 & 0.531 & 0.525 & 0.528 & 0.528 & 0.521 & 0.529 & 0.519 \\
\hline Average $h_{\mathrm{c}} / h$ & 0.521 & 0.521 & 0.524 & 0.523 & 0.523 & 0.524 & 0.523 & 0.520 \\
\hline Force at unloading, $F_{\max }(\mu \mathrm{N})$ & 378 & 378 & 171 & 198 & 198 & 169 & 246 & 176 \\
\hline Contact depth by Ngan's method, $h_{\text {Ngan }}(\mu \mathrm{m})$ & 0.919 & 0.883 & 0.947 & 0.939 & 0.938 & 0.948 & 0.924 & 0.945 \\
\hline
\end{tabular}

